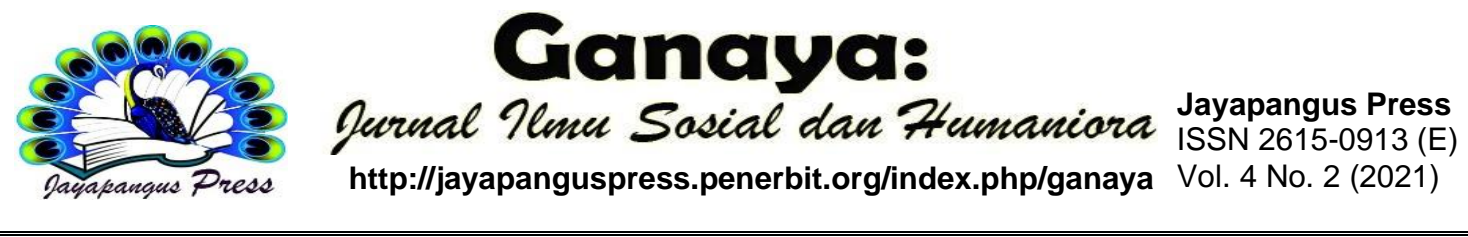

\title{
Pengaruh Advertising Dan Special Event Terhadap Peningkatan Brand Awareness
}

\author{
Rima Rahmani Anwar ${ }^{1}$, Rosita Anggraini T. ${ }^{2}$ \\ ${ }^{1}$ Marketing Communication, STIKOM InterStudi, Jakarta \\ ${ }^{2}$ Communication, STIKOM InterStudi, Jakarta \\ ${ }^{1}$ rachmanirima@gmail.com, ${ }^{2}$ rosita.tagor@gmail.com
}

\begin{tabular}{l}
\hline Keywords: \\
\hline Advertising, \\
Special Event, \\
Brand Awareness \\
\hline
\end{tabular}

Kata Kunci:

Advertising, Special Event, Brand

Awareness.

\begin{abstract}
The right communication to grow brand awareness can be realized through advertising. In addition, events are one of the strategies to have a positive influence in communicating a brand. This study wants finding out how building and increasing brand awareness through advertising on social media Instagram and the "Zumba party" event. This research was conducted at the KALCare Lotte Shopping Avenue outlet using a quantitative approach and a positivism paradigm. The study population was 61 "Zumba party" participants as well as a representative sample. The data was processed with SPSS 20.1. then analyzed using Cronbach's Alpha value test factor analysis and t test for regression test The results showed that the "Zumba party" event had a strong enough influence to increase brand awareness of PT. Kalbe Farma. As for advertising on Twitter, although not significant, it still has an influence to increase brand awareness of PT. Kalbe Farma in low levels. Thus, advertisements on the @ kalcare Instagram account should be maximized in terms of content and frequency in communicating the Kalbe Farma brand in order to be able to grow Brand Awareness. Then for further research to expand the findings of the benefits of advertising and special events in growing Brand Awareness to customers in various industries and also among society in general.
\end{abstract}

\footnotetext{
Abstrak

Komunikasi yang tepat untuk menumbuhkan kesadaran merek dapat diwujudkan dengan kegiatan periklanan (advertising). Selain itu, event adalah cara dan strategi untuk menghasilkan dampak positif terhadap suatu brand. Penelitian ini bertujuan mengetahui cara membangun dan meningkatkan brand awareness melalui iklan / advertising di media sosial Instagram serta event "Zumba party". Penelitian ini dilakukan di outlet KALCare Lotte Shopping Avenue dengan menggunakan metode survey dan analisis kuantitatif serta memakai paradigma positivisme. Populasinya adalah peserta "Zumba party" sebanyak 61 sekaligus sebagai sampel yang mewakili. Data
} 
diolah dengan SPSS 20.1 kemudian dianalisis menggunakan analisis faktor uji nilai Alpha Cronbach dan uji t untuk uji regresi. Hasil penelitian menunjukkan bahwa Event "Zumba party" memiliki pengaruh yang cukup kuat dalam meningkatkan terhadap brand awareness PT. Kalbe Farma. Adapun Iklan/advertising di Instagram meskipun tidak signifikan, tetapi tetap memiliki pengaruh dalam meningkatkan brand awareness PT. Kalbe Farma dalam kadar yang rendah. Dengan demikian, maka iklan di akun Instagram @kalcare hendaknya lebih dimaksimalkan konten dan frekuensinya dalam mengkomunikasikan brand Kalbe Farma agar mampu menumbuhkan Brand Awareness. Kemudian agar penelitian selanjutnya memperluas temuan manfaat advertising dan special event dalam menumbuhkan Brand Awareness pada pelanggan di beragam industri dan juga di masyarakat pada umumnya.

\section{Pendahuluan}

Kesadaran merek (Brand awareness) bisa dimaknai menjadi kapabilitas seseorang dalam menyeleksi satu $\mathrm{brand} /$ merek dengan $\mathrm{brand} /$ merek yang lain dilihat melalui bermacam elemen brand/merek. Menurut Gil et al., (2007) brand awareness (kesadaran merek) dapat dihubungkan dengan kemampuan para pembeli dalam rangka memikirkan dan kenal bahwa sebuah produk dan jasa tersebut merupakan bagian dari suatu brand/merek. Kesadaran merek atau Brand awareness juga mampu menunjukkan fungsi yang berharga untuk melahirkan ekuitas/persamaan merek yang berlandas pada pembeli (Purwianti, 2018).

Adapun bentuk penyampaian pesan untuk menimbulkan brand awareness (kesadaran merek) secara optimal adalah melalui kegiatan periklanan (advertising) (Herdana, 2015). Meski tidak langsung berpengaruh dalam penjualan, iklan menjadi alat efektif dalam mendukung komunikasi pemasaran bagi perusahaan dalam membidik pesaing dan membentuk brand awareness (Lukitaningsih, 2013). Iklan menjadi bagian dari paduan promosi (promotion mix) dan paduan promosi adalah suatu bentuk elemen yang berada pada paduan pemasaran (marketing mix) (Herdana, 2015). Ketika beriklan, suatu perusahaan bisa memilih media untuk menyampaikan pesan (Lukitaningsih, 2013). Pemanfaatan social media begitu penting untuk produsen, dalam mendukung akses komunikasi pemasaran di tengah, ekspansi bisnis, dan pengembangan iklan (Tasruddin, 2016). Oleh karena itu, dalam mencapai tingkat brand awareness (kesadaran merek)-nya, PT. Kalbe Farma, sebuah industri produk maupun jasa yang menangani cabang obatobatan membuat iklan di media sosial baik di facebook, di twitter dan Instagram dengan nama KALCare seperti tertera pada gambar 1. 


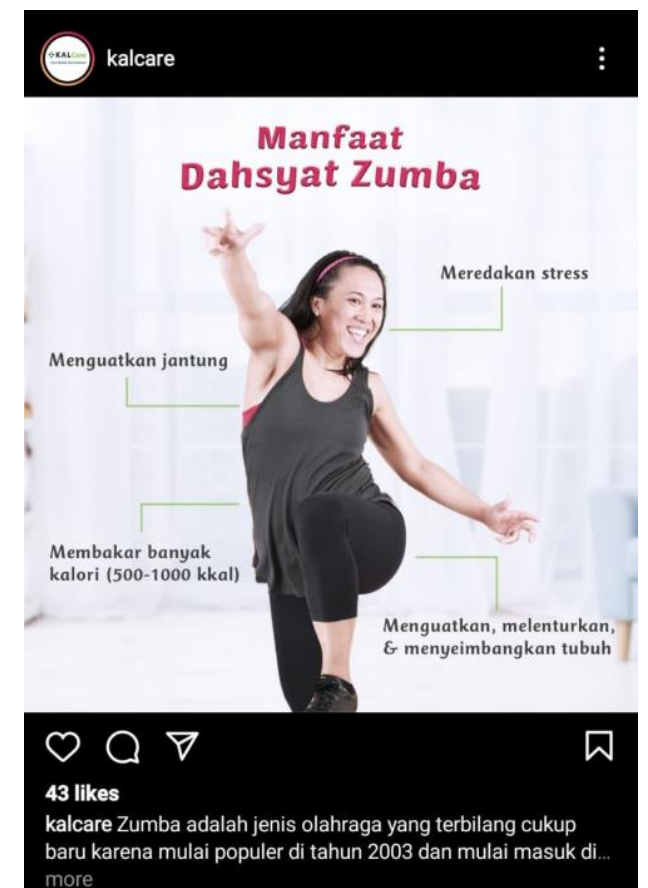

Gambar 1. Iklan KalCare di Instagram

(Sumber: https://www.instagram.com/kalcare/)

Selain advertising, event juga menjadi suatu cara yang mampu menghasilkan dampak baik dan cenderung dominan untuk menginformasikan merek terhadap calon pembeli (Astuti, 2011). Dengan kata lain, brand/merek bisa dibentuk oleh banyak faktor dan mampu dikomunikasikan melalui aspek Komunikasi Pemasaran Terpada (IMC), salah satunya melalui penyelenggaraan sebuah event (Astuti, 2011). Event merupakan bagian dari bauran promosi (promotion mix) yang menjadi media bagi perusahaan serta menjadi cara alternatif untuk dapat menyampaikan pesan suatu produk kepada konsumen secara langsung (Ningrum, 2016). Sedangkan membuat suatu acara atau kegiatan khusus oleh humas yang bisa menghasilkan respon masyarakat pada organisasi atau produk/jasa tertentu disebut special events (Muhammad Reza, 2018).

Oleh karena itu, PT. Kalbe Farma juga memanfaatkan event untuk menjadi strategi dalam menghadapi persaingan yang ketat. PT. Kalbe Farma membuat sebuah event bernama "Zumba party" melalui program Slim \& Fit 30 days challenge di setiap outlet KALCare di seluruh cabang. Program ini bertujuan untuk menginformasikan bahwa brand PT. Kalbe Farma memiliki keunikan dan diferensiasi yang bisa membedakan produknya dengan produk pesaing lainnya. Melaui event "Zumba party" ini, PT. Kalbe Farma berharap supaya khalayak bisa mengaplikasikan "Cara serta pola hidup yang Sehat (https://m.facebook.com/KALCareID/posts/885020698361171). 
Jurnal penelitian yang dijadikan rujukan serta cara mengadopsi variabelvariabelnya sebagai instrumen dalam penelitian ini terdiri dari tiga penelitian sebelumnya. Penelitian pertama disusun oleh (Muhammad Reza, 2018) yang menunjukkan bahwa terdapat persepsi positif dari para responden tentang Program acara khusus bernama “Mix Your Team”. Kemudian, responden juga memiliki persepsi positif tentang pengetahuan produk "Noble Nation ICafe" (Muhammad Reza, 2018). Penelitian ke dua dibuat oleh (Bangun \& Saputri, 2016) yang menunjukkan hasil bahwa iklan yang dibuat Zalora mempunyai dampak kepada Brand awareness/kesadaran merek, di mana jumlah koefisiennya sebesar $73,4 \%$. Adapun $26,4 \%$-nya dipengaruhi oleh elemen dan faktor lainnya yang tidak sempat dieksplor dalam jurnal ini (Bangun \& Saputri, 2016). Jurnal ilmiah ke tiga dibuat oleh (Ghealita Vevi, 2015) di Kota Bandung. Adapun hasil yang diperoleh terdapat pengaruh brand awareness (kesadaran merek) dalam menimbulkan keputusan pembelian AMDK merek Aqua sebanyak 70,1\%. Adapun berlandaskan variabel brand awareness (kesadaran merek) dilihat dari koefisien determinasi bisa memberikan dampak keputusan pembelian sebesar 46,2\% (Ghealita Vevi, 2015). Berdasarkan penelitian terdahulu tersebut, maka dapat dihipotesiskan :

H1 : Iklan / advertising di Instagram memiliki pengaruh terhadap brand awareness PT. Kalbe Farma. :

H2 : Event "Zumba party" memiliki pengaruh terhadap brand awareness PT. Kalbe Farma.

Penelitian ini bertujuan mengetahui dampak dan pengaruh pemanfaatan iklan/advertising di media sosial serta penyelenggaraan sebuah event bernama "Zumba party" dalam meningkatkan brand awareness dengan melakukan penelitian di outlet KALCare Lotte Shopping Avenue Jakarta Pusat.

\section{Metode}

Penelitian ini adalah penelitian eksplanatif dengan menggunakan metode survey. Penelitian ini memiliki maksud untuk melacak dan memandang ada tidaknya dan seberapa kuat hubungan atau pengaruh yang terbentuk (Hasanah, 2016). penelitian ini menggunakan pendekatan kuantitatif serta paradigma positivism, yakni mempunyai maksud untuk membuka tirai kejadian atau kenyataan sosial yang terjadi melalui proses penyandaran pada observasi mengenai kenyataan kemasyarakatan di sekitar lingkungan (Kusuma \& Prasetio, 2016). 
Populasi dalam jurnal ilmiah ini yaitu para orang yang mendatangi event Zumba party yang dilaksanakan di KALCare Lotte Shopping Avenue dengan jumlah peserta sebanyak 61 orang (Data Event, 2018). Sampel merupakan setengah bagian dari populasi yang diseleksi melalui cara atau metode khusus, dengan harapan bisa merepresentasikan populasi (Girsang, 2019). Jumlah sampel pada penelitian ini sebanyak 61 orang menggunakan sampling jenuh atau istilah lainnya yakni sensus, yaitu semua anggota populasi dijadikan sampel (Khoerudin et al., 2018).

Pengumpulan data dengan menggunakan kuesioner, (Poluan et al., 2016). Data yang diperoleh kemudian diolah dengan pengolahan data pada jurnal ilmiah ini yang memanfaatkan Teknik paket statistic SPSS20.0. Sebagai cara dalam menganalisis hasil temuan pada jurnal ilmiah ini adalah teknik Analisis faktor untuk uji validitasnya, dengan dengan membandingkan nilai Cronbach Alpha > 0,6 untuk uji reliabilitasdan menggunakan uji t untuk uji Regresi Linear Sederhana (Syamsudin \& Pratiwi, 2019).

\section{Hasil dan Pembahasan}

Responden pada jurnal ilmiah ini berjumlah 61. mayoritas responden adalah wanita $(88,5 \%)$, dengan rata-rata usia antara $31-40$ tahun (70,5\%). Lebih dari setengah responden berpendidikan S1 $(55,7 \%)$ dan berprofesi sebagai pegawai swasta $(36,1 \%)$ dengan penghasilan antara $10 \mathrm{~s} / \mathrm{d} 15$ juta perbulan $(29,5 \%)$.

Tahap uji validitas menunjukkan bahwa variabel Advertising, Special Event dan Brand Awareness memiliki nilai Keiser Meyer Olkin (KMO) yang lebih tinggi dari 0,5. Maka itu, bisa dikatakan yakni seluruh variabel validitasnya relevan (Boonlertvanich, 2019). Adapun nilai Alpha Cronbach (a) variabel Advertising, Special Event dan Brand Awareness menunjukkan angka di atas ambang batas 0.6. Dengan demikian dapat ditetapkan bahwa semua variabel reliabel (Cakici et al, 2019). Lebih jelasnya bisa diperhatikan melalui tabel 1 di bawah ini.

Tabel 1. Validitas \& Reliabilitas Variabel

\begin{tabular}{cccc}
\hline Variabel & KMO & A & Keterangan \\
\hline A & 0.866 & 0.930 & Valid \& Reliabel \\
SE & 0.883 & 0.933 & Valid \& Reliabel \\
BA & 0.756 & 0.867 & Valid \& Reliabel \\
\hline
\end{tabular}

Note: A (Advertising), SE(Special Event), BA (Brand Awareness)

Sumber : Peneliti (2020) 
Nilai Koefisien Determinasi $\left(\mathrm{R}^{2}\right)$ pada jurnal ilmiah ini menunjukkan hubungan yang rendah dengan persentase 38,5\% seperti tertera pada tabel 2 berikut ini.

Tabel 2. Nilai Koefisien Determinasi

\begin{tabular}{|c|c|c|c|c|}
\hline Model & $\mathbf{R}$ & $\begin{array}{c}\mathbf{R} \\
\text { Square }\end{array}$ & $\begin{array}{l}\text { Adjusted } \\
\text { R Square }\end{array}$ & $\begin{array}{c}\text { Std. Error of the } \\
\text { estimate }\end{array}$ \\
\hline 1 & 0.620 & 0.385 & 0.364 & 0,39864 \\
\hline
\end{tabular}

Sumber : Peneliti (2020)

Nilai tersebut menunjukkan bahwa Brand Awareness dalam tataran yang rendah bisa dijelaskan oleh variabel Advertising dan Special Event, sedangkan 61,5\% lainnya yang merupakan residu dari Advertising dan Special Event diuraikan oleh elemen atau hal-hal lain yang tidak tercantum pada penelitian ini. Lebih jelasnya bisa diperhatikan melalui gambar 2 di bawah ini:

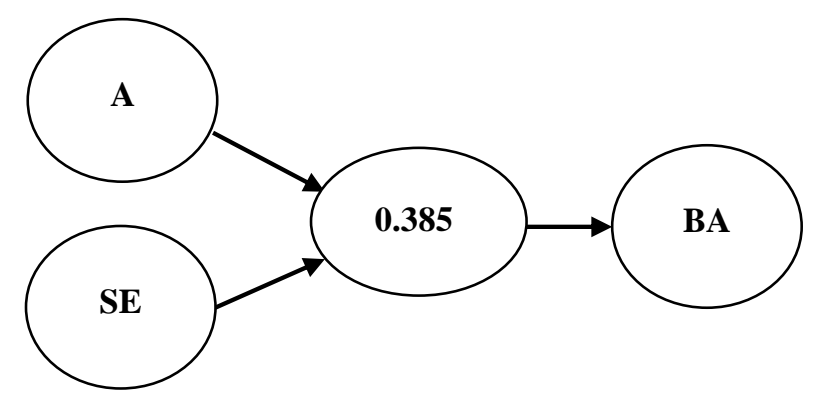

Gambar 2. Nilai $\mathrm{R}^{2}$ A, SE terhadap BA

Sumber : Peneliti (2020)

Gambar 2 di atas mengilustrasikan bahwa Advertising dan Special Event, keduanya memiliki pengaruh dalam membentuk dan meningkatkan Brand Awareness. Hal ini, relevan dengan suatu penelitian milik Handayani (2009) yang menjelaskan mengenai repetisi pesan iklan mempunyai dampak baik pada kesadaran merek (Brand awareness) (Putra \& Mudiantono, 2014). Kemudian hasil ini juga sejalan dengan pernyataan bahwa special event yang diselenggarakan perusahaan bisa melahirkan kesan mendalam kepada setiap konsumen yang hadir, sehingga konsumen dan konsumen yang potensial mampu mengingat dengan jelas mengenai kesan-kesan yang menghibur dan bisa aware kepada produk serta merek tersebut (Ningrum, 2016).

Berdasarkan uji hipotesis diketahui bahwa tidak semua hipotesis yang diajukan terbukti karena uji regresi linear hanya menunjukkan angka signifikasi 0.000 untuk H2 ( $\mathrm{SE}->\mathrm{BA}$ ) yang mengindikasikan $\mathrm{H} 2$ signifikan dan terbukti secara statistik. Uji hipotesis pertama yakni H1 (A -> BA) menunjukkan angka sig. 0.155 yang berarti bahwa 
Iklan/advertising di Instagram tidak berpengaruh signifikan terhadap brand awareness PT. Kalbe Farma sedangkan uji hipotesis ke dua yakni H2 (SE -> BA) menunjukkan angka sig. 0.014 yang berarti adanya pengaruh signifikan Event "Zumba party" terhadap brand awareness PT. Kalbe Farma. Untuk mengetahui lebih detailnya, bisa diperhatikan pada tabel 3 di bawah ini.

Tabel 3. Uji Hipotesis

\begin{tabular}{lccc}
\hline \multicolumn{1}{c}{ Hypotesis } & $\begin{array}{c}\text { Standardized } \\
\text { Coeffient (Beta) }\end{array}$ & Sig. & Result \\
\hline H1 & 0.237 & 0.155 & $\begin{array}{c}\text { Not } \\
\text { significant }\end{array}$ \\
A $->$ BA & & & \\
H2 & 0.417 & 0.014 & Significant \\
SE -> BA & & & \\
\hline
\end{tabular}

Sumber : Peneliti (2020)

Hasil yang menunjukkan bahwa H1 (A -> BA) ditolak dapat dihubungkan nilai Standardized Coeffient (Beta) Iklan / advertising terhadap brand awareness sebesar 0,237 yang berarti Iklan / advertising di Instagram memiliki pengaruh yang rendah dalam meningkatkan brand awareness PT. Kalbe Farma. Walaupun kadar pengaruh ini rendah, namun tetap mencerminkan hasil bahwa di era digital ini menjadi banyak trend yang berubah, termasuk misalnya terhadap bisnis advertising atau iklan di Indonesia yang terus menggunakan internet agar bertambah maju di tiap posisinya. Social media pun sekarang sudah membentuk gaya dan acuan yang amat jitu pada bidang komunikasi pemasaran dan periklanan (Putra \& Mudiantono, 2014). Dengan demikian, kehadiran media baru, seperti media sosial bisa memberi suatu kemajuan pada bidang komunikasi pemasaran dan menjadi suatu metode jitu dan sakti untuk mengiklankan karakteristik dan kelebihan suatu brand atau merek produk (Tasruddin, 2016).

Nilai Standardized Coeffient (Beta) Special event terhadap brand awareness sebesar 0,417 berarti Event "Zumba party" memiliki pengaruh yang cukup kuat dalam meningkatkan terhadap brand awareness PT. Kalbe Farma. Dengan bisa dimaknai bahwa Event "Zumba party" menjadi suatu sarana informasi $P R$ yang bisa menghasilkan berita dengan segera dan sudah disusun dengan terorganisir melalui tampilan packaging yang disukai (Likebility). Kemudian juga, Event "Zumba party" mampu memajukan suatu pengetahuan (knowledge) serta kesadaran (awareness) demi upaya pemenuhan selera 
(pleasure), serta menciptakan rasa hangat dari pelanggan yang pada akhirnya bisa menghasilkan citra (image) dan menimbulkan pengertian kedua pihak (Muhammad Reza, 2018). Ilustrasi uji hipotesis $\mathrm{H} 1$ dan $\mathrm{H} 2$ bisa diperhatikan melalui gambar 3 berikut ini:

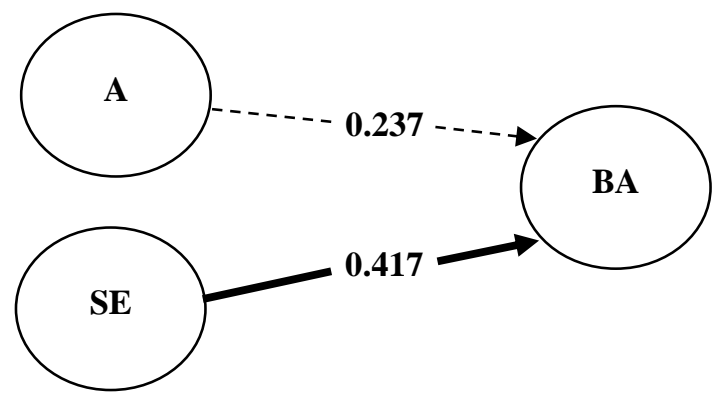

Gambar 3. Nilai Beta A, SE terhadap BA

Sumber : Peneliti (2020)

Hasil penelitian ini yang menunjukkan bahwa Iklan / advertising di Instagram tidak memiliki pengaruh signifikan dalam meningkatkan brand awareness PT. Kalbe Farma berlawanan dengan jurnal ilmiah yang dilaksanakan terlebih dahulu yang menjelaskan mengenai Iklan/advertising memiliki pengaruh secara kuat dalam menumbuhkan Brand awareness pada Zalora Indonesia (Bangun \& Saputri, 2016). Namun demikian dan meskipun tidak signifikan, tetapi Iklan / advertising di Instagram tetap memiliki pengaruh meningkatkan brand awareness PT. Kalbe Farma walaupun dalam kadar yang rendah yang berarti bahwa Iklan yang disuguhkan kepada konsumen dengan bahasa lugas dan artikulasi jelas akan mudah difahami oleh orang yang melihatnya. Selain itu, penyampaian konten iklan yang memanfaatkan bahasa yang jelas dan tidak ber-kiasan dapat menumbuhkan awareness di benak konsumen.

Hal ini tentunya relevan dengan Abdurrahman (2015) bahwa Advertising atau iklan berpengaruh secara kuat dalam menumbuhkan brand awareness atau kesadaran merek. Walaupun publikasi dan perdagangan pribadi serta promosi perdagangan pun mampu menumbuhkan penjualan. Namun brand awareness atau kesadaran merek pembeli harus diperhitungkan dalam rangka menumbuhkan tingkat konsumsi dan itu semua terpulang dengan metode pembentukan brand awareness di mana salah satunya adalah dengan memanfaatkan iklan (Bangun \& Saputri, 2016).

Uji hipotesis H2 (SE -> BA) yang menunjukkan hasil adanya pengaruh signifikan Event "Zumba party" terhadap brand awareness PT. Kalbe Farma relevan dengan sebuah penelitian yang menemukan hasil mengenai Event, Brand Image dan brand awareness di 
mana ke duanya memiliki sinergi yang linier dan satu arah serta berdampak pada Minat Beli (Ningrum, 2016). Hasil ini juga sesuai dengan penelitian milik Wulandari yang dilaksanakan di Kabupaten Jember yang membuahkan hasil tentang adanya dampak positif yang signifikan pada program Acara Pagelaran Budaya dan Seni BBJ 2012 terhadap Brand Awareness Kabupaten Jember (Wulandari Deasy, Imam Suroso, 2013). Selain itu, Event “Zumba party" dapat dikatakan telah menjalani konsep Goldblatt (2014) mengenai lima tahap atau langkah yang perlu dijalankan dalam rangka mewujudkan program kegiatan khusus yang bermanfaat dan sesuai tujuan yaitu: 1) Research (penelitian), 2). Design (kreasi), 3). Planning (persiapan), 4). Coordinating (kerjasama) dan 5) Evaluation (penilaian) (Hartono, Dida, Hafiar, \& Km, 2016).

Pada akhirnya, penelitian ini juga menunjukkan hasil bahwa apabila suatu kesadaran merek atau brand awareness tinggi, maka akan memiliki dampak pada ketentuan pembelian seseorang pada produk tersebut. keadaan demikian bia tercapai karena brand atau merek tersebut telah sampai pada tangga top of mind dan telah menjadi hal yang amat terarah pada alam bawah sadar seseorang, sehingga para pembeli menjadikan merek tersebut untuk pilihan pertama waktu hendak mengkonsumsi produk yang diinginkannya (Ghealita Vevi, 2015).

\section{Kesimpulan}

Dari semua pemaparan dan deskripsi di dalam bagian-bagian di atas, maka bisa dipaparkan suatu summary bahwa Iklan/advertising di Instagram memiliki pengaruh yang rendah dalam meningkatkan brand awareness PT. Kalbe Farma. Sedangkan Event "Zumba party" memiliki pengaruh yang cukup kuat dalam meningkatkan terhadap brand awareness PT. Kalbe Farma. Sebagai bentuk saran, maka Iklan / advertising di akun Instagram @kalcare hendaknya lebih dimaksimalkan konten dan frekuensinya dalam mengkomunikasikan brand Kalbe Farma agar mampu menumbuhkan Brand Awareness. Kemudian agar memperluas temuan manfaat advertising dan special event dalam menumbuhkan Brand Awareness pada pelanggan di beragam industri dan juga di kalangan masyarakat pada umumnya. 


\section{Daftar Pustaka}

Anwar, A., Bakti, I., \& Budiana, H. R. (2018). MANAJEMEN SPECIAL EVENT HALLYU COME ON SPECIAL MANAGEMENT OF HALLYU COME ON. MetaCommunication; Journal Of Communication Studies. Vol 3 No 1 Maret 2018. Bandung: Universitas Padjajaran, Program Studi Ilmu Komunikasi ., 3(1). Retrieved from http://ppjp.unlam.ac.id/journal/index.php/MC/article/view/4707/4106

Asbullah, A. S. (2015). EVENT MARKETING SEBAGAI STRATEGI MENINGKATKAN BRAND AWARENESS KABUPATEN JEMBER. UNIVERSITAS JEMBER FAKULTAS EKONOMI, 9(1), 43-55.

Astuti, P. A. A. (2011). Membangun Merek Melalui Penyelenggaraan Sebuah Event: Studi Kasus Pada Event “Sour Sally Just Wanna Have Fun”. Jurnal Komunikasi, Volume 1, Nomor 2, Januari 2011. Jakarta: Universitas Pelita Harapan Program Studi Ilmu Komunikasi, 1(2), 183. https://doi.org/10.24329/aspikom.v1i2.17

Bangun, B. T., \& Saputri, M. E. (2016). PENGARUH ADVERTISING TERHADAP PEMBENTUKAN BRAND AWARENESS PADA ZALORA INDONESIA. eProceeding of Management: Vol.3, No.2 Agustus 2016 | Page 2076. Bandung: Universitas Telkom Program Studi Ilmu Komunikasi, Fakultas Komunikasi Dan Bisnis., 3(2), 2079.

Boonlertvanich. (2019). Service quality, satisfaction, trust, and loyalty: the moderating role of main-bank and wealth status. International Journal of Bank Marketing, 37(1), 278-302. https://doi.org/10.1108/IJBM-02-2018-0021

Cakici et al. (2019). The impact of perceived price justice and satisfaction on loyalty: the mediating effect of revisit intention. Tourism Review, 74(3), 443-462. https://doi.org/10.1108/TR-02-2018-0025

Errika Dwi Setya Watie. (2012). PERIKLANAN DALAM MEDIA BARU (Advertising In The New Media ) THE MESSENGER, Volume IV, Nomor 1, Edisi Januari 2012. Universitas Semarang: Jurusan Ilmu Komunikasi, IV, 37-43.

Ghealita Vevi, R. S. (2015). PENGARUH BRAND AWARENESS TERHADAP KEPUTUSAN PEMBELIAN AMDK MEREK AQUA (Studi Pada Masyarakat di Kota Bandung). Bandung: Universitas Telkom Program Studi Ilmu Komunikasi, Fakultas Komunikasi Dan Bisnis., 32(5), 754. https://doi.org/10.11164/jjsps.32.5_754_2 
Girsang, H. (2019). PENGARUH MARKETING PUBLIC RELATION DAN BRAND IMAGE TERHADAP LOYALITAS PELANGGAN (Studi Pada PT. JNE Cabang Samosir). JOM FISIP Vol. 6: Edisi I Januari - Juni 2019. Universitas Riau Universitas Riau: Fakultas Ilmu Sosial Dan IlmuPolitik: Program Studi Administrasi Bisnis- Jurusan Ilmu Administrasi., Vol. 6, h. 1-15. https://doi.org/10.1017/CBO9781107415324.004

Hartono, N. A., Dida, S., Hafiar, H., \& Km, S. (2016). PELAKSANAAN KEGIATAN SPECIAL EVENT JAKARTA GOES PINK OLEH LOVEPINK INDONESIA Komunikasi, Vol. X No. 02, September 2016: 161-172. Bandung: Universitas Padjajaran, Program Studi Ilmu Komunikasi ., 161-172.

Hasanah, F. (2016). PENGARUH PELAYANAN PRIMA TERHADAP KEPUASAN PELANGGAN DI JADE BAMBOO RESTO YOGYAKARTAj Jurnal KELUARGA Vol 2 No 1 Februari 2016. Prodi PKK JPTK FKIP UST, 2(1). Retrieved from https://core.ac.uk/download/pdf/230376964.pdf

Herdana, A. (2015). Analisis Pengaruh Kesadaran Merek (Brand Awareness) Pada Produk Asuransi Jiwa Prudential Life Assurance (Studi Pada Pru Passion Agency Jakarta). Jurnal Riset Bisnis dan Manajemen Vol.3 ,No.1, 2015:1-18. Universitas Sam Ratulangi: Program Magister Manajemen Fakutas Ekonomi Dan Bisnis, $3(1), 1-18$.

Khoerudin et al. (2018). KOORDINASI EKSTERNAL DINAS LALU LINTAS DAN ANGKUTAN JALAN TENTANG IMPLEMENTASI SISTEM SATU ARAH DIKOTA BOGOR. Jurnal GOVERNANSI ISSN 2442-3971 Volume 3 Nomor 2, Oktober 2017. Bogor Universitas Djuanda Fakultas Ilmu Sosial Dan Ilmu Politik lJurusan Ilmu Administrasi Negara, 3(2), 63-70. https://doi.org/10.30997/jgs.v3i2.920

Kusuma, S. I., \& Prasetio, A. (2016). PROSES PUBLIC RELATIONS PT . POS INDONESIA DALAM MEMPERTAHANKAN CITRA TERKAIT BEREDARNYA TABLOID OBOR RAKYAT. e-Proceeding of Management : Vol.3, No.2 Agustus 2016 | Page 2359. Bandung: Universitas Telkom Program Studi Ilmu Komunikasi, Fakultas Komunikasi Dan Bisnis., 3(2), 2359-2368. 
Lukitaningsih, A. (2013). IKLAN YANG EFEKTIF SEBAGAI STRATEGI KOMUNIKASI PEMASARAN. Jurnal Ekonomi dan Kewirausahaan Vol. 13, No. 2, Oktober 2013: 116 - 129. Yogyakarta: Universitas Sarjanawiyata Tamansiswa, Fakultas Ekonomi ., 13(2), 116-129. Retrieved from http://ejurnal.unisri.ac.id/index.php/Ekonomi/article/view/670/576

Muhammad Reza, H. L. (2018). Persepsi Peserta Special Event Mix Your Team mengenai Product Knowledge Noble Nation ICafe (Studi Deskriptif Kuantitatif Mengenai Persepsi Product Knowledge Noble Nation ICafe dari Special Event Mix Your Team Pada Kalangan Peserta). MEDAN: UNIVERSITAS SUMATERA UTARA, DEPARTEMEN ILMU KOMUNIKASI FAKULTAS ILMU SOSIAL DAN ILMU POLITIK.

Ningrum, N. (2016). Pengaruh Event Dan Brand Image Terhadap Minat Beli Produk Rokok Sampoerna a Mild Pada Pt Hm Sampoerna. e-Jurnal Manajemen Kinerja E-ISSN : 2407-7305. Vol.2, Nomor 1 Januari 2016. Surabaya: Universitas Narotama, Fakultas Ekonomi \& Bisnis., 2(1), 1-13. Retrieved from https://jurnal.narotama.ac.id/index.php/manajemenkinerja/article/view/95

Poluan et al. (2016). PENGARUH PERIKLANAN TERHADAP KEPUTUSAN PEMBELIAN MINUMAN COCA COLA (STUDI KASUS PADA PT. BANGUN WENANG BEVERAGE COMPANY MANADO). Jurnal EMBA Vol.4 No.3 September 2016, Hal. 671-681. Universitas Sam Ratulangi ManadoFakultas Ekonomi Dan Bisnis, Jurusan Manajemen, 4(3), 671-681.

Purwianti, L. (2018). Faktor - faktor yang Mempengaruhi Brand Equity pada Pemilik Mobil di Batam. Journal of Accounting \& Management Innovation, Vol.2 No.2, July 2018, pp. 170-186. Batam: Universitas Internasional Batam, 2(2), 170-186.

Putra, A. R. A., \& Mudiantono. (2014). ANALISIS PENGARUH DAYA TARIK PESAN IKLAN, PERSEPSI KEMANFAATAN, CITRA MEREK PADA MEDIA SOSIAL TWITTER TERHADAP PEMBENTUKAN BRAND AWARENESS(Studi Kasus pada Media Sosial Twitter @ infoUNDIP. atau Info Undip Media). DIPONEGORO JOURNAL OF MANAGEMENT Volume 3,. Universitas Diponegoro: Jurusan ManajemenFakultas Ekonomika Dan Bisnis., $3,1-12$. 
Suabhakti, Y. B. B., Widiarto, \& Desi, S. R. (2014). PENGARUH DAYA TARIK IKLAN, EFEK KOMUNITAS, DAN BRAND ACTIVATION TERHADAP BRAND AWARENESS SIMCARD GSM PRA BAYAR IM3 (Studi Kasus Pada Mahasiswa Program Sarjana FISIP Undip Semarang). Universitas Diponegoro: Fakultas Ilmu Sosial Dan Ilmu Politik., 3, 1-17. Retrieved from http://digilib.uinsby.ac.id/24531/7/Roby Johan Falah_B76213085.pdf

Syamsudin \& Pratiwi. (2019). PELAYANAN PRIMA FRONT OFFICE SEBAGAI UPAYA MENINGKATKAN KEPUASAN PELANGGAN EXTERNAL PADA NEC UTAN KAYU JAKARTA. JURNAL ILMU PENGETAHUAN DAN TEKNOLOGI KOMPUTER. VOL. 4. NO. 2 FEBRUARI 2019. E-ISSN: 25274864. Universitas Bina Sarana Informatika, 4(2), 23-28.

Tasruddin, R. (2016). TREN PERIKLANAN DI MEDIA SOSIAL. Jurnal Komodifikasi Volume 5, Juni 2017, hal 15-20. Makassar: Universitas Islam Negeri Alauddin, Fakultas Dakwah Dan Komunikasi., 15-20. Retrieved from http://journal.uinalauddin.ac.id/index.php/Komodifikasi/article/view/5504\#

Wulandari Deasy, Imam Suroso, A. S. A. (2013). EVENT MARKETING SEBAGAI STRATEGI MENINGKATKAN BRAND AWARENESS. Jurnal Bisnis dan Manajemen Vol. 9, No. 1 Januari 2015 Hal. 43 - 55. JEMBER: UNIVERSITAS JEMBER FAKULTAS EKONOMI. 